\title{
EL DRAGÓN, SÍMBOLO POR EXCELENCIA DE LA VIDA Y LA MUERTE ENTRE LOS MAYAS
}

Mercedes DE LA GARZA Centro de Estudios Mayas

Fertilidad es vida, potencialidad y realización de la vida, y la vida fue el bien por excelencia para los mayas antiguos, por lo que la fertilidad, tanto la de la naturaleza como la del hombre, entendida como energía sagrada, fue su preocupación principal. De este modo, las más importantes manifestaciones y símbolos de lo sagrado fueron aquellas que propiciaban la fertilidad y que mantenían la vida. Pero la fertilidad lleva en sí misma la muerte en una armonía de contrarios, por lo que los símbolos mayas de la fertilidad, como potencia de vida en el universo, conllevan la fuerza de muerte.

Hay diversos símbolos de la fertilidad en el pensamiento religioso maya, pero el fundamental es la serpiente, y sobre todo la víbora cascabel tropical o Crotalus Durissus durissus, que tiene en el dorso un diseño de rombos (figura 1). El cuerpo mismo del ofidio representa el falo, y los rombos, el sexo femenino, por lo que simbólicamente es un ser andrógino, encarnación de la potencia de vida; pero a la vez representa el poder de la muerte por su veneno, fulminante como el rayo que acompaña a la tormenta.

Y una serpiente transformada en dragón, es decir, enriquecida con rasgos de otros animales poderosos, como plumas y alas de quetzal, garras de lagarto o de jaguar y pezuñas de venado, fue para los mayas el símbolo por excelencia de la energía o poder sagrado que, con la carga ambivalente de vida y muerte, bien y mal, masculino y femenino, anima las tres dimensiones espacio-temporales del cosmos: el cielo, la tierra y el inframundo (figura 2).

El dragón no fue, como lo creímos antes, una deidad sólo celeste, ${ }^{1}$ sino que parece haber simbolizado la fertilidad del cosmos íntegro, un

' Véase De la Garza, El universo... 


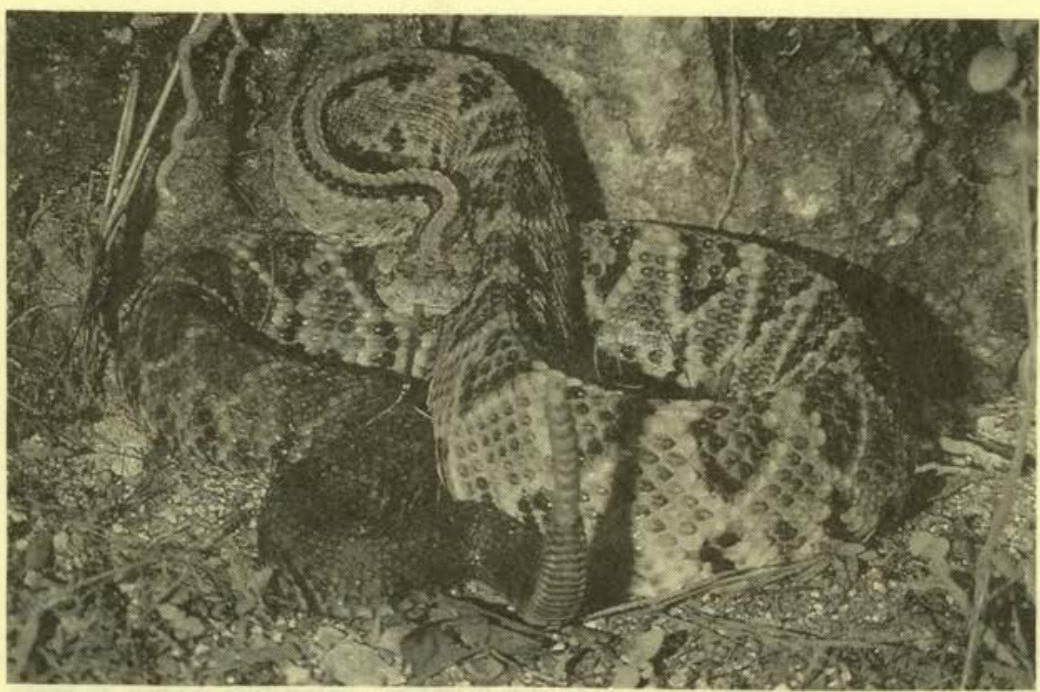

Figura 1. Serpiente Crotalus Durissus durissus

poder que no se concreta en un dios determinado, sino que se manifiesta en varias figuras divinas a la vez, constituyendo la conjugación de los grandes contrarios de la naturaleza, que es la dinámica de la vida del cosmos. $^{2}$

Llamamos dragón a este ser fantástico porque combina rasgos de diversos animales, fundamentalmente serpiente y ave, predominando el carácter serpentino, como ocurre con los dragones europeos y los asiáticos. El término proviene del sustantivo latino drácon, 'serpiente', que deriva a su vez del verbo dercomai, el cual define la intensidad de la mirada, fija y paralizante de la serpiente. Drácon equivale a ophis, ofidio. Por ello se denominaron dragones las serpientes maléficas de la mitología medieval europea, los seres sepentinos fantásticos de Persia y otros sitios del Asia menor, y también las divinidades benéficas de China y Japón, en las que se conjugan rasgos de serpiente y ave (figura 3). Así dragón se ha convertido en un término universal, y es el que más precisamente define ese símbolo serpentino, uno de cuyos aspectos más notables es la serpiente emplumada, que se encuentra en la mayoría de las culturas mesoamericanas.

${ }^{2}$ El dragón en China es también la conjugación de los contrarios: es yang como símbolo del trueno y de la primavera, de la actividad celeste, y es yin como soberano de las regiones acuáticas. 


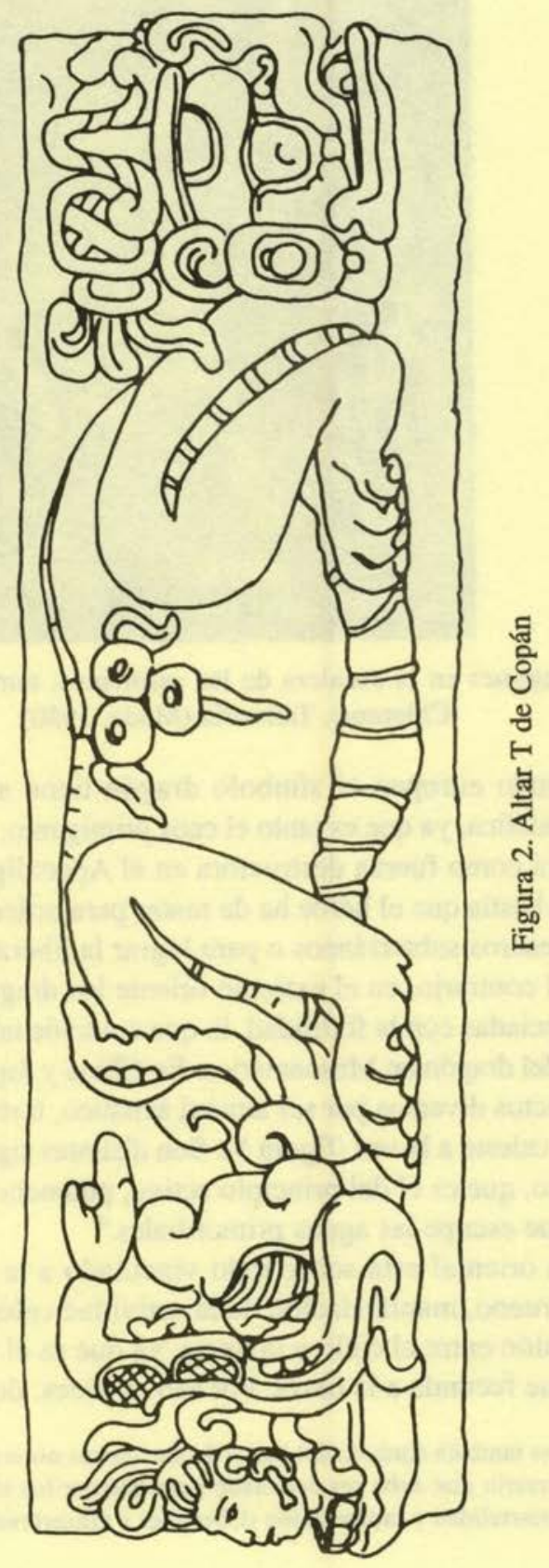

Estudios de Cultura Maya. Vol. XX, 1999

Instituto de Investigaciones Filológicas/

Centro de Estudios Mayas, UNAM 


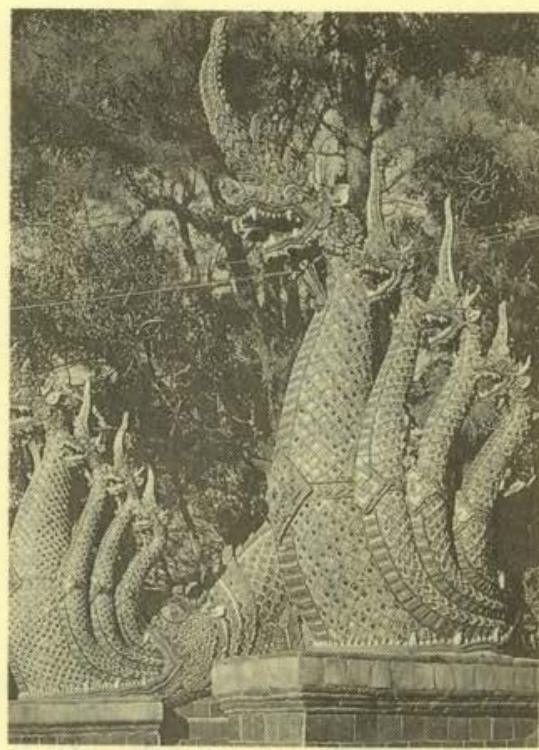

Figura 3. Dragones en la escalera de las serpientes, templo de Wat Suthep Chienmai, Tailandia (Mode, 1980)

En el mundo europeo el símbolo dragón tiene ante todo una significación maléfica, ya que es tanto el caos primigenio, como el monstruo que aparecerá como fuerza destructora en el Apocalipsis (figura 4). Es, asimismo, la bestia que el héroe ha de matar para ordenar el mundo, para obtener los tesoros subterráneos o para lograr la liberación o la inmortalidad. ${ }^{3}$ Por el contrario, en el extremo oriente los dragones son deidades benéficas asociadas con la fertilidad, lo que coincide notablemente con el simbolismo del dragón en Mesoamérica. En China y Japón el dragón tiene también aspectos diversos por ser animal acuático, terrestre —quizá subterráneo- y celeste a la vez (figura 5). Son distintas significaciones de un símbolo único, que es el del principio activo, potencia de vida y a la vez de muerte, que escupe las aguas primordiales. ${ }^{4}$

El dragón oriental está sobre todo vinculado a la producción de la lluvia y del trueno, manifestación de la actividad celeste. Su función es de lazo de unión entre el cielo y la tierra, ya que es el símbolo de la lluvia celeste que fecunda a la tierra. Por eso, a veces, de sus fauces abier-

${ }^{3} \mathrm{El}$ dragón es también símbolo del mal y de las fuerzas oscuras e irracionales de la psique. El adversario que debe ser derrotado para obtener los tesoros escondidos, el secreto de la inmortalidad y la liberación (Chevalier y Gheerbrant).

${ }^{4}$ Ibidem. 


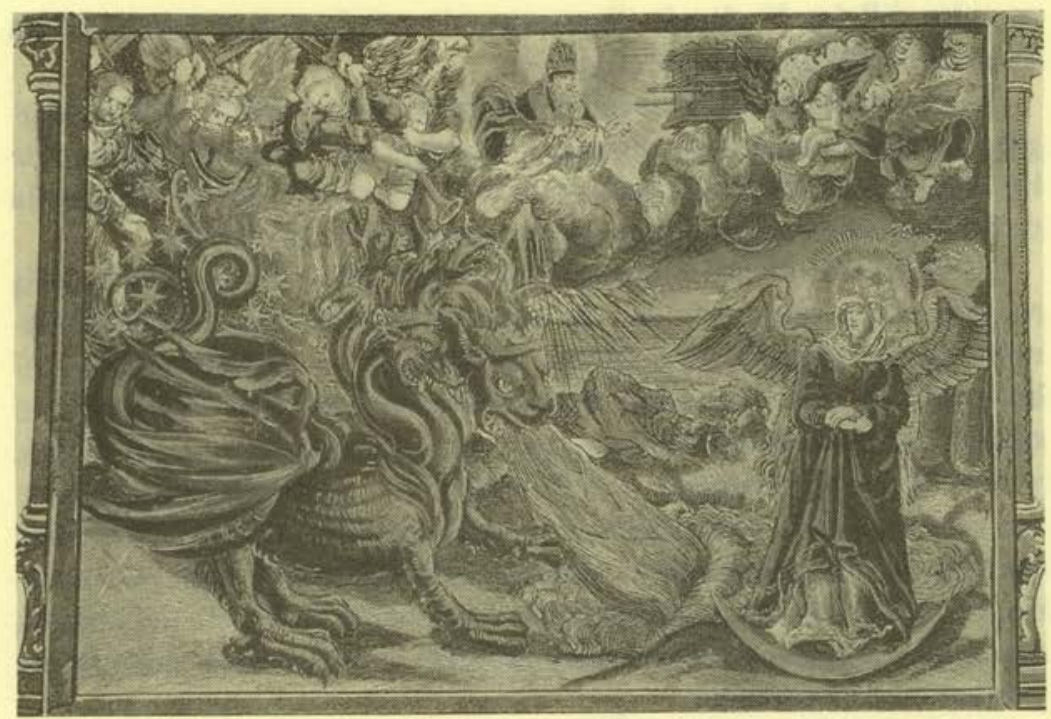

Figura 4. Dragón del Apocalipsis de San Juan, Biblia de Cranach, Biblioteca Zerbst (Mode, 1980)

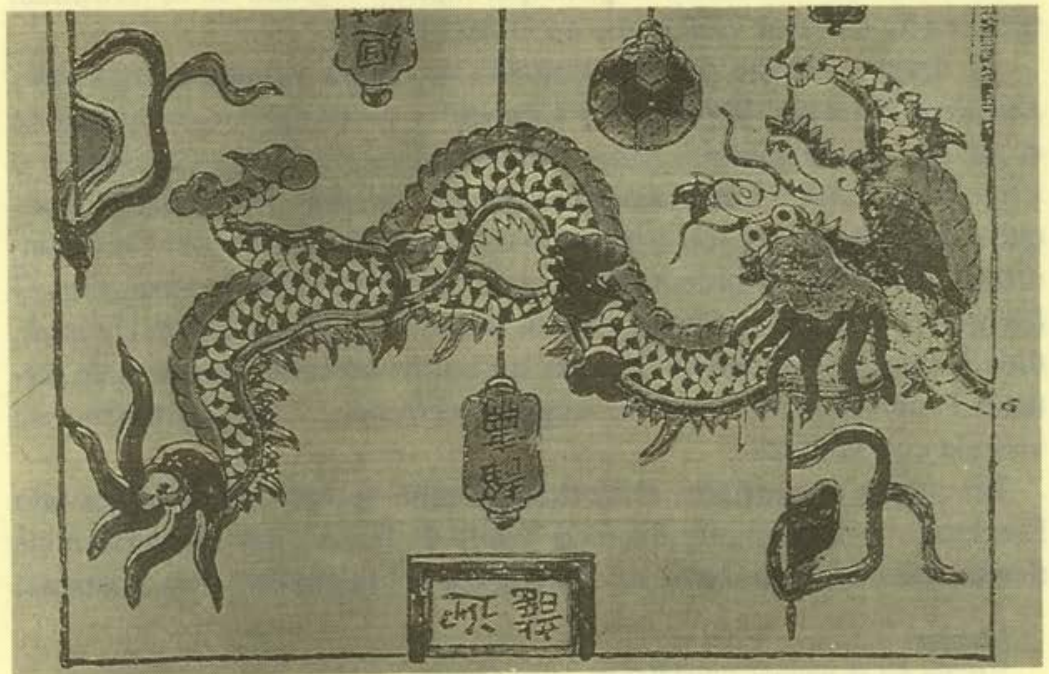

Figura 5. Dragón en una tarjeta china de Año Nuevo (Mode, 1980)

Estudios de Cultura Maya. Vol. XX, 1999 Instituto de Investigaciones Filológicas/

Centro de Estudios Mayas, UNAM

ISSN 0185-2574

http://www iifilologicas unam mx/estculmava/ 
tas salen follajes. Y además, como potencia creadora, el dragón en China es símbolo del emperador ${ }^{5}$ (figura 6).

En el mundo mesoamericano encontramos estos significados del dragón, aunque también hay algunas coincidencias con el simbolismo de los dragones occidentales, principalmente el hecho de ser vehículo de la transfiguración espiritual del hombre, maestro de iniciación.

La definición de los dioses es tarea muy difícil en el estudio de la religión maya, pues cada uno de los seres sagrados tiene diversas manifestaciones y múltiples nombres, de acuerdo con sus atributos y, sobre todo, con la temporalidad. Para el maya no hay seres estáticos, todo está en constante movimiento y, por tanto, cambiando. Así, los dioses, y con ellos sus influencias, son diferentes en cada momento. Por eso, son celestes y terrestres, benéficos y maléficos, masculinos y femeninos, energías de vida y energías de muerte. Cada elemento integra su contrario, pues es resultado de una peculiar concepción dialéctica del mundo, que asume la lucha y armonía de contrarios como el motor que origina y mantiene la existencia.

El dragón es, así, un ser sagrado múltiple y polivalente. Su carácter celeste se expresa con alas y plumas; el terrestre, con símbolos de vegetación y rasgos de cocodrilo, y el infraterrestre, con huesos y otros símbolos de muerte. Pero esto tampoco es uniforme, pues a veces el carácter destructivo del dragón celeste se representa con signos de muerte. Y en todas sus formas, el dragón se vincula con agua, por lo que fundamentalmente simboliza el principal líquido sagrado de la fertilidad, tanto en su carácter vital como en el destructivo.

El dragón celeste fue denominado en maya yucateco Itzam $\mathrm{Na}$, Kukulcán (Quetzal-Serpiente) y Canhel, ${ }^{6}$ y el terrestre, que integra en sí mismo al inframundo, Itzam Cab Ain (Dragón-Tierra-Cocodrilo) o Chac Mumul Ain (Gran Cocodrilo Lodoso). Además, hay otras deidades que a nuestro parecer son aspectos o derivaciones del dragón: Chicchan, dios H (Serpiente Mordedora), el cielo nocturno; Kinich Ahau, dios G (Señor del Ojo Solar); Chaac, dios B, dios de la lluvia, y Bolon Dz'acab, dios K (Nueve Generaciones), que simboliza aspectos humanos de fertilidad sacralizados, como la sangre y el semen, y que, asimismo, se vincula con el maíz.

En cuanto a su origen, el símbolo dragón aparece desde el periodo Preclásico en el gran arte llamado "estilo de Izapa", que floreció en las tierras altas del área maya, un poco antes del inicio de la era cristiana.

${ }^{5}$ Ibidem.

${ }^{6}$ Itzam $\mathrm{Na}$ se traduce simplemente como "Dragón". Véase abajo el significado de Canhel. 


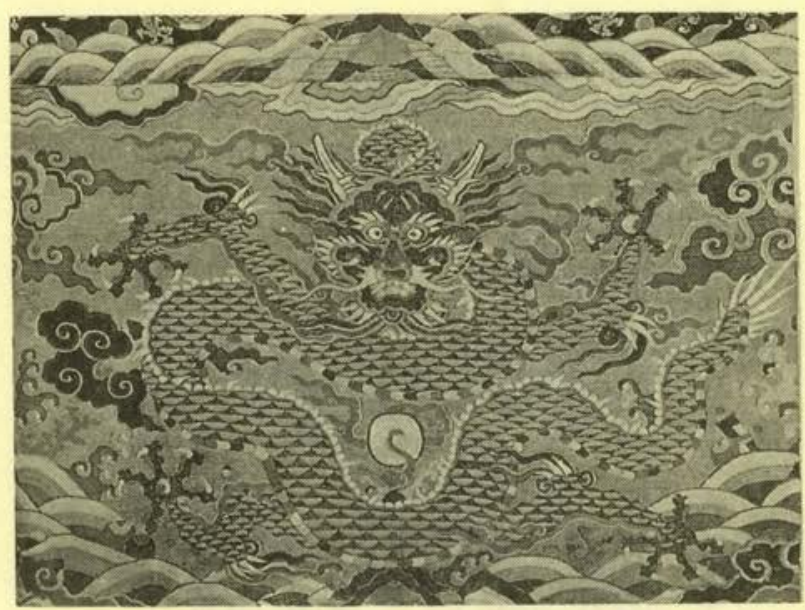

Figura 6. Dragón imperial con cinco dedos, dinastía Ming (New Larousse Encyclopedia of Mythology)

En las obras escultóricas de ese estilo encontramos frecuentemente la representación del animal fantástico que integra rasgos de serpiente, ave, jaguar y lagarto (figura 7). Esos animales fueron elegidos por los hombres de Izapa para simbolizar la sacralidad del universo, representada por las fuerzas naturales de las que el hombre agricultor depende para su existencia material. Por ello, los contextos en los que encontramos al dragón aluden, por lo general, a la fertilidad. Así, el dragón del estilo de Izapa puede ser celeste, terrestre o acuático.

En los sitios que pertenecen a este estilo, el dragón también se antropomorfiza, es decir, adquiere rasgos humanos, surgiendo así el antecedente del dios maya de la lluvia, Chaac, que esgrime su hacharayo ante otro gigantesco dragón con cuerpo de serpiente (figura 8). Son las fuerzas sagradas de la fecundidad cósmica en un juego dialéctico, en el que también el dragón-fertilidad se torna símbolo de la muerte, para significar la dinámica de muerte y renacimiento que rige al universo.

En la religión maya, que encontramos ya plenamente diferenciada en la tercera centuria después de Cristo, el símbolo dragón se consolida como el de la energía sagrada de la fertilidad del universo, que incluye su contrario: la muerte. Con diversas variantes formales en su representación plástica, el dragón aparece en obras de todas las regiones del área maya y durante todo el periodo prehispánico.

Tiene además un aspecto antropozoomorfo, que funge como héroe cultural, el llamado dios D de los códices (figura 9), que se dibuja como 


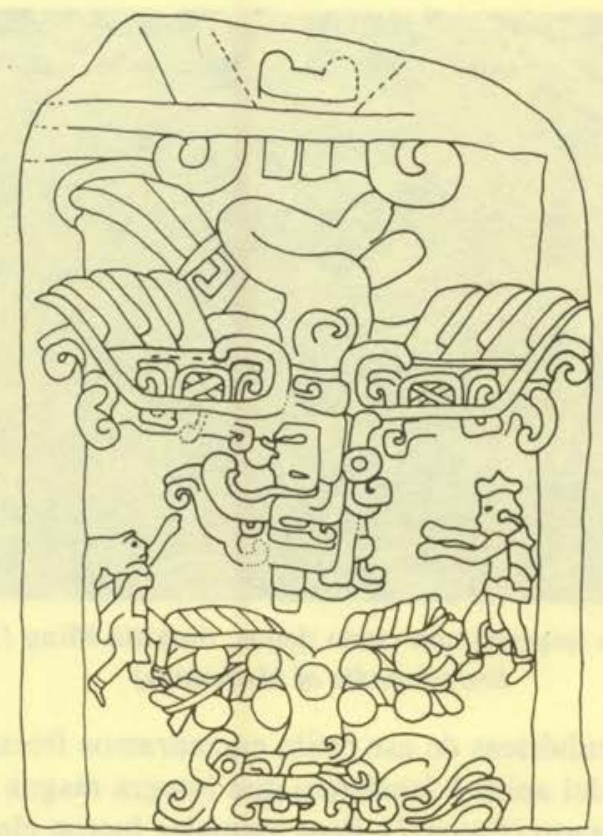

Figura 7. Estela 2 de Izapa

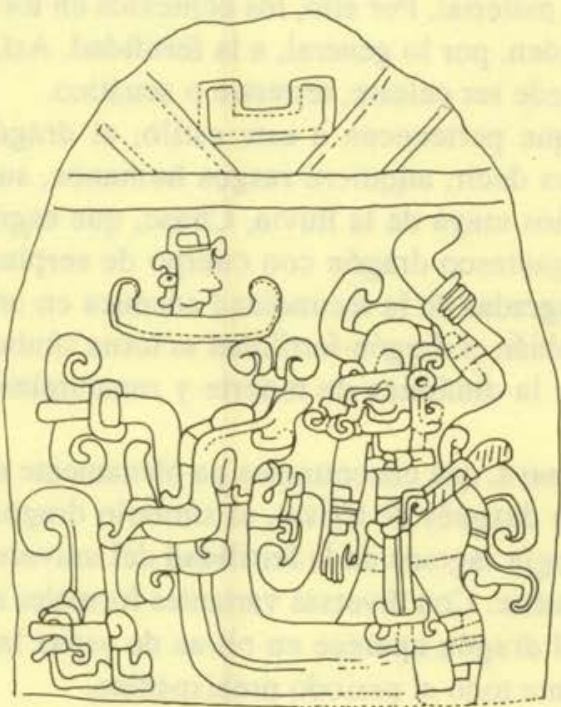

Figura 8. Estela 3 de Izapa

Estudios de Cultura Maya. Vol. XX, 1999 Instituto de Investigaciones Filológicas/

Centro de Estudios Mayas, UNAM 
un anciano con ojo serpentino, nariz roma y boca desdentada, al que se ha relacionado con el Itzam $\mathrm{Na}$, "El dragón" que mencionan los textos coloniales; ${ }^{7}$ es un dios celeste de naturaleza fundamentalmente acuática, ya que el nombre significa también "Brujo del agua", y era "el que recibe y posee la gracia, o rocío, o sustancia del cielo", según Lizana. ${ }^{8}$ Es, además, un dios creador y héroe cultural, que da a los hombres sus conocimientos (se decía que inventó la agricultura, la escritura, los calendarios y las demás creaciones humanas), dicta sus leyes y gobierna a través de sus elegidos.

Las fuentes escritas registran distintos nombres añadidos al de Itzam $\mathrm{Na}$, que aluden a sus varias funciones y que corroboran que las otras deidades que hemos mencionado son aspectos suyos: Kauil (El de la buena cosecha); Tul, Conejo (El de la lluvia perjudicial); Kabul (El productor con sus manos), aspecto creador, y Kinich Ahau (El rostro u ojo del Sol). ${ }^{9}$

En tanto que dios creador, el dragón es serpiente emplumada y se llama Canhel, como aparece en los mitos cosmogónicos de los Libros de Chilam Balam, y Gucumatz, en el Popol Vuh. En ambos casos, el nombre significa serpiente emplumada. ${ }^{10}$ En el Popol Vuh es símbolo del agua primordial, principio vital de los dioses creadores, y en el Chilam Balam de Chumayel es la energía vital ubicada en el treceavo cielo, que al ser robada por los dioses del inframundo, acarrea la destrucción del cosmos.

El dragón celeste (figura 10) es principalmente la combinación de los atributos de la serpiente y el ave, ya que el ofidio - que por su propia naturaleza es morador de las profundidades de la tierra, donde encarna la potencia vital del falo - al ascender transfigurado por las cualidades del ave, transporta al cielo la energía fecundante, que ha de retornar a la tierra en forma de lluvia para hacer surgir de ella la vida.

El dragón celeste se representa como serpiente emplumada o alada, muchas veces bicéfala; como serpiente-lagarto emplumado bicéfalo y como pájaro-serpiente. Siempre lleva plumas y frecuentemente el signo de bandas cruzadas, que es uno de los glifos del cielo. Se concibe

7 Paul Schellhas, Representation...

${ }^{8}$ Lizana, Historia de Yucatán..., p. 4.

9 Véase Eric Thompson, Historia y religión de los mayas.

${ }^{10}$ Mediz Bolio traduce Canhel como "Serpiente de vida". Y el texto del Chumayel añade: "con los cascabeles de su cola (zabac)... y ...sus plumas de quetzal (ix kukil, ix yaxum)" (Chilam Balam de Chumayel, en De la Garza, Literatura maya, p. 242). Las traducciones de Barrera Vásquez y de Roys coinciden en que el nombre se refiere a la serpiente-quetzal (véase De la Garza, Aves sagradas de los mayas, p. 32, nota 20). 


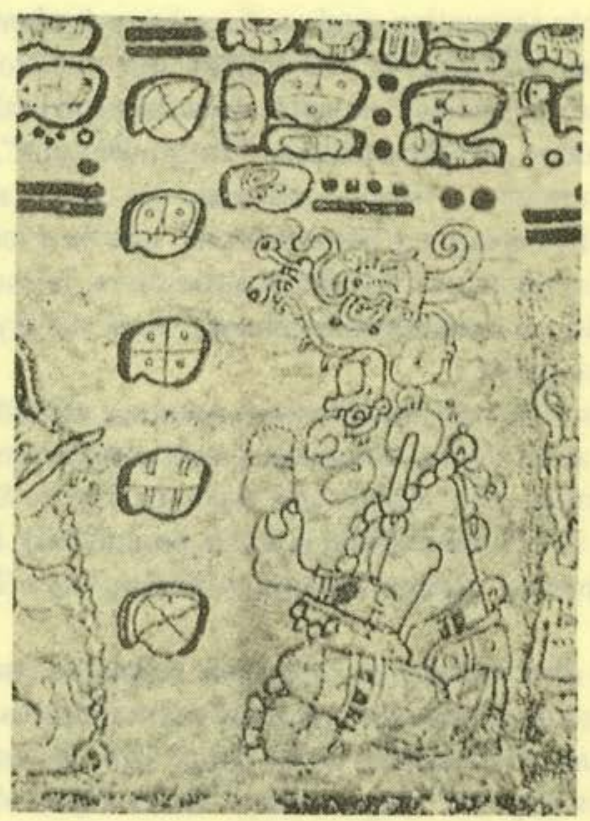

Figura 9. Códice de Dresde, dios D, p. 5c2

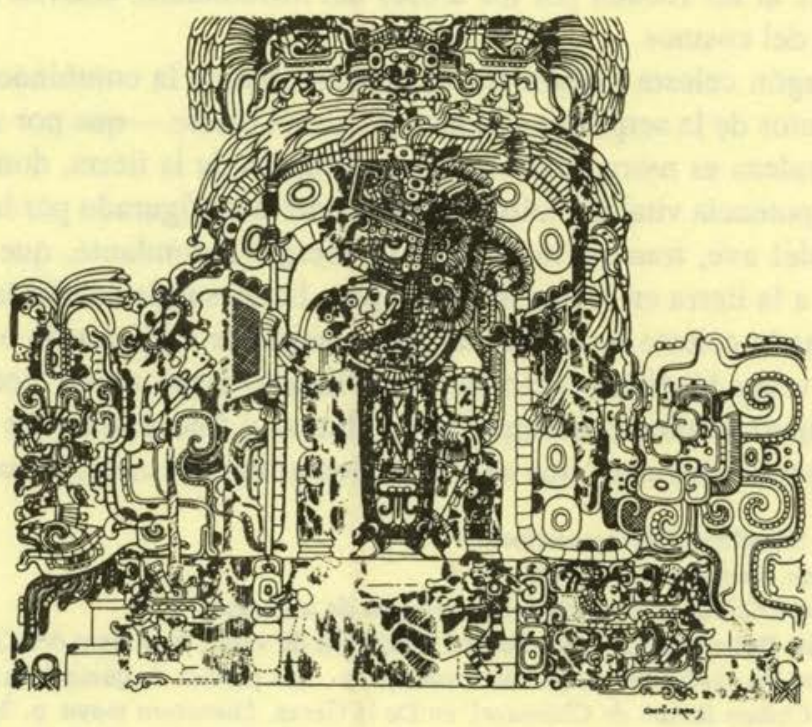

Figura 10. Dintel 3 del templo IV de Tikal 
como uno y cuatro a la vez, de los colores de los rumbos cósmicos, o sea que ocupa las cuatro partes del ámbito celeste.

En los códices, su cuerpo se esquematiza en una faja con los signos de los astros, que simboliza asimismo la vía láctea, ${ }^{11}$ ubicándose hacia lo alto, hacia el cielo, desde donde sus enormes fauces serpentinas arrojan agua sobre la tierra (figura 11). A veces, de la propia banda astral cae lluvia, y otros signos de agua (como flamas, círculos y plumas) adornan el cuerpo del monstruo.

También en algunos relieves, como el del Templo de la Cruz de Palenque (figura 12) se representa la banda astral como cuerpo del dragón, que en vez de cara de serpiente tiene un mascarón descarnado, aludiendo a su dualidad como símbolo de vida y de muerte, de cielo y a la vez de inframundo. Sobre él, al lado del signo del cielo, formando una tríada simbólica, aparece una concha, que alude al origen, y una espina para el autosacrificio, que pudiera representar la sangre, elementos que, como los acuáticos, nos muestran que el monstruo celeste simboliza la energía fecundante del cielo más que el cielo mismo. Y bajo ese símbolo triádico vemos el glifo del Sol, lo que muestra que éste es un aspecto del dragón.

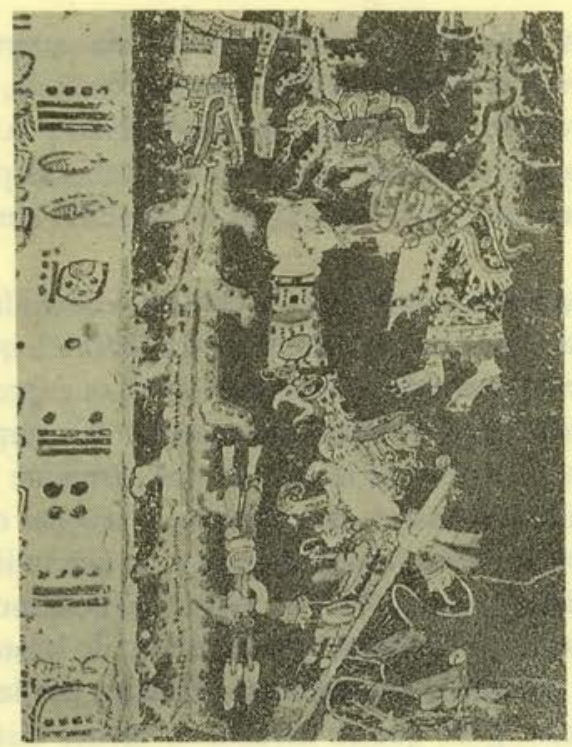

Figura 11. Códice de Dresde, p. 74

"Véase John Sosa, "Astronomía sin telescopios..." 


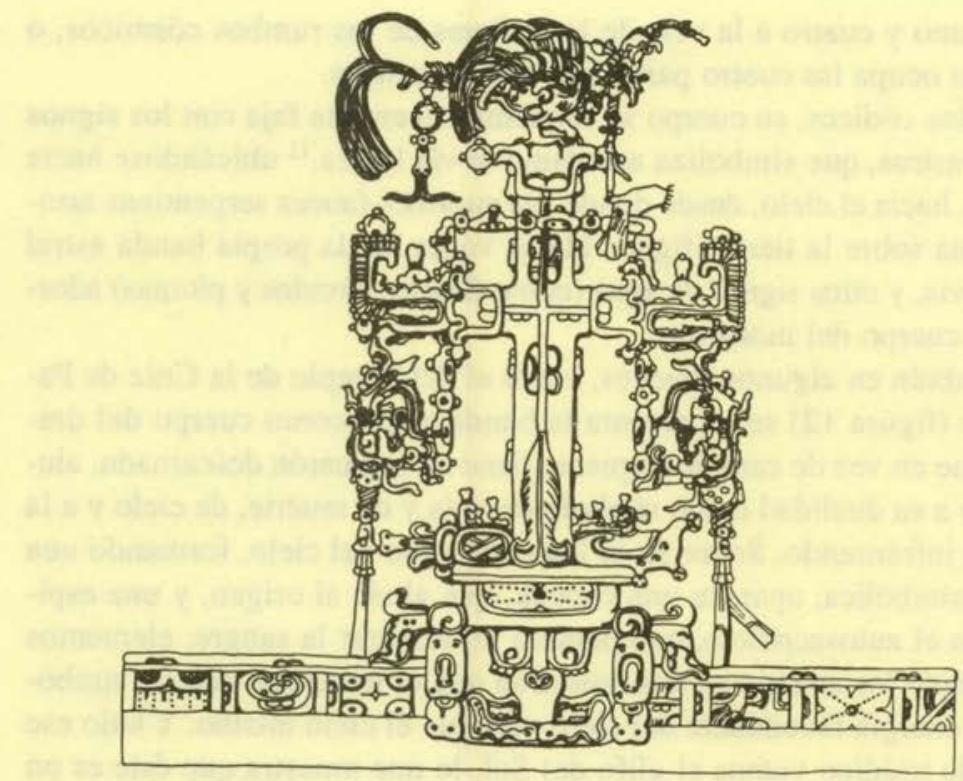

Figura 12. Motivo central del tablero del Templo de la Cruz, Palenque

Otra expresión, muy clara, de la dualidad vida-muerte, cielo-inframundo del dragón es la imagen de una serpiente bicéfala, con cuerpo de banda astral, una cabeza que arroja agua hacia abajo y la otra descarnada que mira hacia arriba (figura 13). Estas dos cabezas pudieran significar también una armonía de contrarios en relación con la fertilidad: sequía y lluvia.

Hay otra deidad antropomorfa de los códices, conocida como dios $\mathrm{H}$ e identificada con Chicchan, "Serpiente Mordedora", que es también una deificación de la serpiente de cascabel, como se expresa en el augurio o profecía para el día Chicchan, que asienta: "La serpiente del crótalo es su anuncio". Su glifo es la cara de una serpiente fantástica con un círculo sombreado en la sien, que aparece en muchas otras representaciones de serpientes; tiene rasgos de jaguar, lo que indica su carácter de noche y oscuridad (figura 14). Por todo ello, podemos afirmar que Chichan es un aspecto del dragón, el lado oscuro de Itzam $\mathrm{Na}$, es decir, el cielo nocturno; y también se relaciona con agua, por la presencia del glifoYax en su frente, glifo que en muchas imágenes distintas identifica al dragón, indicando su aspecto acuático, que es el principal. Así, el dragón celeste integra otros dos contrarios, cielo diurno y cielo nocturno. 


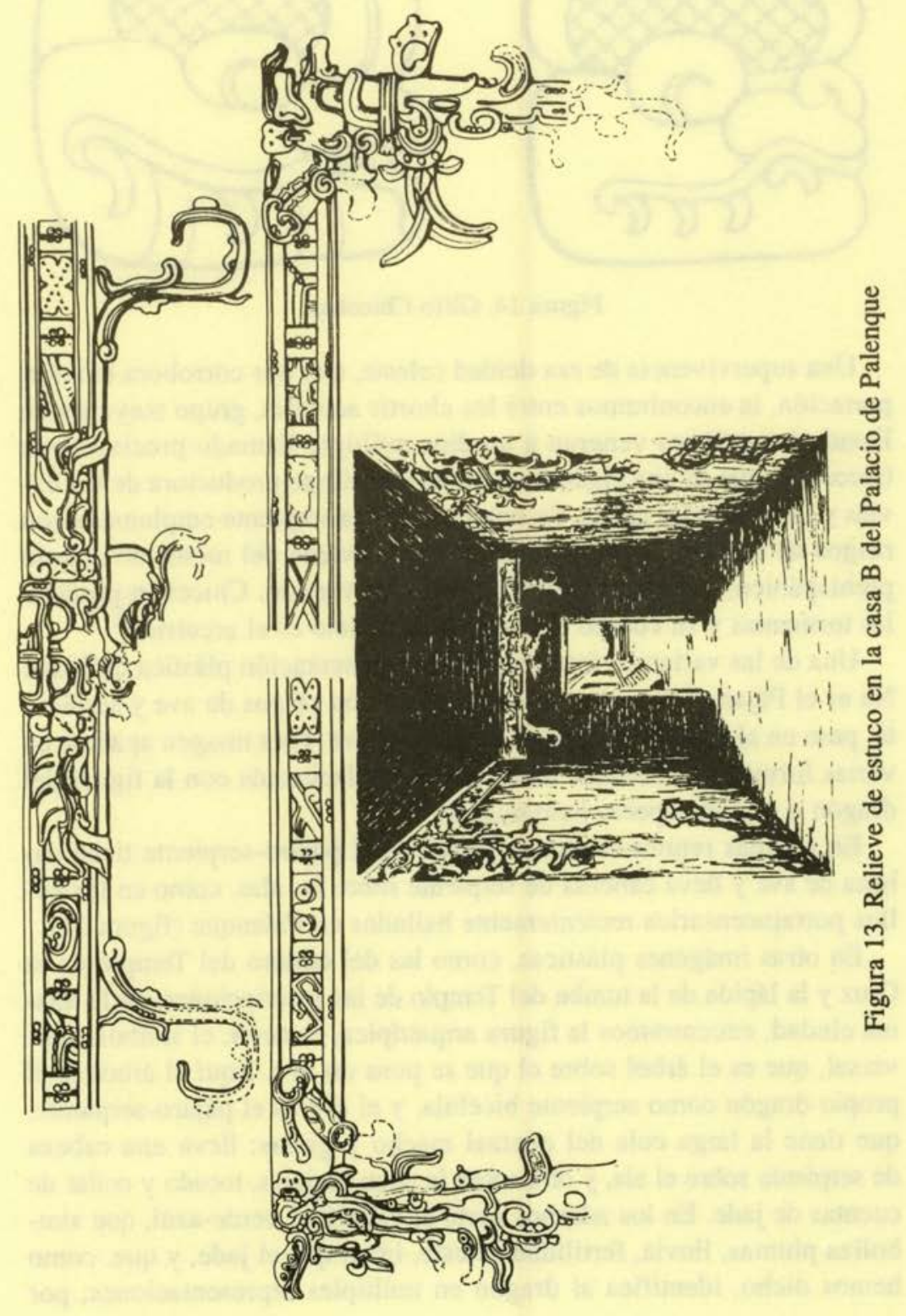

Estudios de Cultura Maya. Vol. XX, 1999

Instituto de Investigaciones Filológicas/

Centro de Estudios Mayas, UNAM

ISSN 0185-2574 

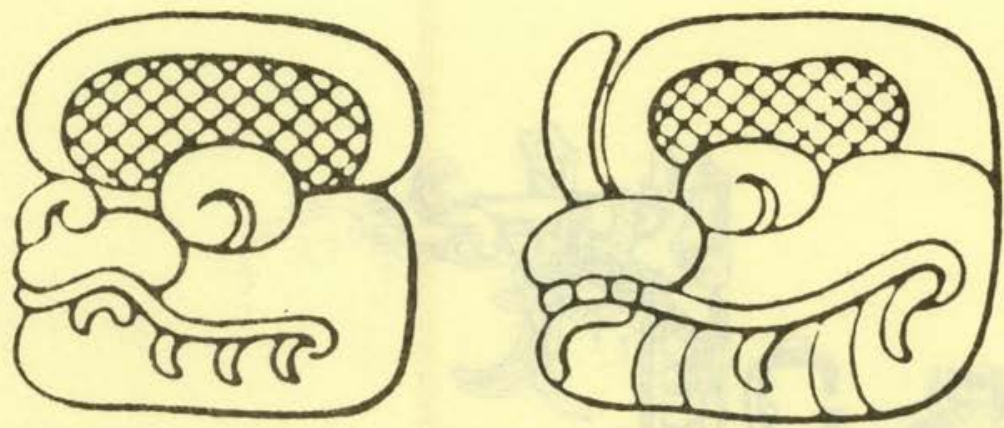

Figura 14. Glifo Chicchan

Una supervivencia de esa deidad celeste, que nos corrobora la interpretación, la encontramos entre los chortís actuales, grupo mayance de Honduras, quienes veneran a un dios múltiple llamado precisamente Chicchan, que es una gigantesca serpiente celeste productora de las lluvias y señora de las aguas. Su nombre alude a serpiente emplumada con rasgos de venado, lo que confirma que proviene del monstruo celeste prehispánico, que tiene también rasgos de venado. Chicchan produce las tormentas y su cuerpo extendido en el cielo es el arcoiris. ${ }^{12}$

Una de las variantes formales en la representación plástica de Itzam $\mathrm{Na}$ es el Pájaro-Serpiente, un ser también con rasgos de ave y serpiente, pero en el que predomina el aspecto de ave. Esta imagen aparece en varias formas y contextos, muchas veces relacionada con la figura del dragón o con su aspecto humanizado. ${ }^{13}$

En algunas representaciones plásticas, el pájaro-serpiente tiene cabeza de ave y lleva cabezas de serpiente sobre las alas, como en los bellos portaincensarios recientemente hallados en Palenque (figura 15).

En otras imágenes plásticas, como las del tablero del Templo de la Cruz y la lápida de la tumba del Templo de las Inscripciones, en la misma ciudad, encontramos la figura arquetípica, es decir, el símbolo universal, que es el árbol sobre el que se posa un ave. Aquí el árbol es el propio dragón como serpiente bicéfala, y el ave es el pájaro-serpiente, que tiene la larga cola del quetzal macho y garras; lleva una cabeza de serpiente sobre el ala, y otra sobre la cola; orejeras, tocado y collar de cuentas de jade. En los adornos porta el glifo Yax, verde-azul, que simboliza plumas, lluvia, fertilidad celeste, igual que el jade, y que, como hemos dicho, identifica al dragón en múltiples representaciones; por

${ }^{12}$ Wisdom, Los chortís de Guatemala.

${ }^{13} \mathrm{De}$ la Garza, Aves sagradas..., cap. I. 


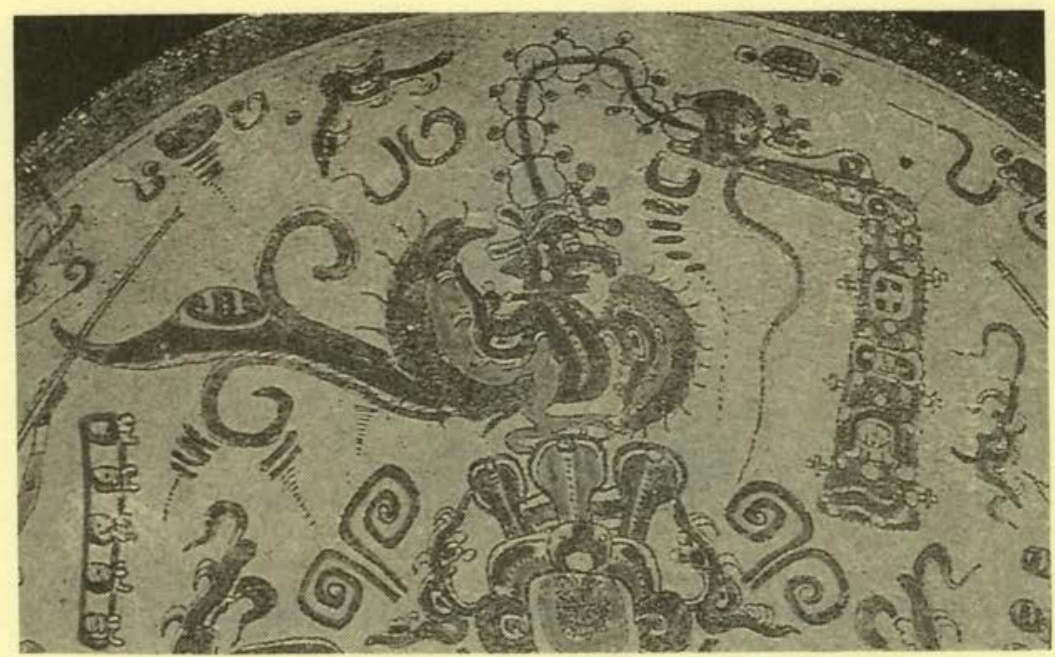

Figura 15. Detalle de un portaincensario de Palenque

ejemplo, forma el cuerpo de la serpiente bicéfala flexible en el propio Tablero de la Cruz y en los códices es parte del tocado del dios D, lo que corrobora que el Pájaro-Serpiente es un aspecto del dragón celeste (figura 12).

Pero la cara del pájaro es muchas veces la de otra deidad: el dios K, Bolon Dz'acab, que presenta varios rasgos serpentinos: el llamado por algunos "ojo divino" porque lo tienen casi todas las deidades, que es el ojo de la serpiente con pupila en forma de voluta, la escama supraorbital, la larga nariz a veces bifurcada o el adorno sobre el pico (que es derivación de la mandíbula superior del ofidio) y el colmillo enrollado de la serpiente en la comisura de la boca o del pico, que aparece también en otras deidades asociadas con el dragón, como Chaac, dios de la lluvia, y Kinich Ahau, deidad solar.

Así, consideramos que el pájaro-serpiente es una variante del dragón celeste, y se asocia con el dios $\mathrm{K}$ por llevar los rasgos de su cara en varias imágenes. La relación del dragón con el dios $\mathrm{K}$ nos presenta a éste como otro aspecto de la deidad suprema, tal como lo interpretó Thompson, aunque él llegó a esta conclusión por otras vías. ${ }^{14}$

$\mathrm{El}$ dios $\mathrm{K}$ se representa muchas veces en figurillas que sostienen los gobernantes o en bastones y cetros maniquí, con cuerpo humano, cara serpentina y una pierna o el pene convertidos en serpiente (figura 16).

14 Thompson, Historia y religión... 


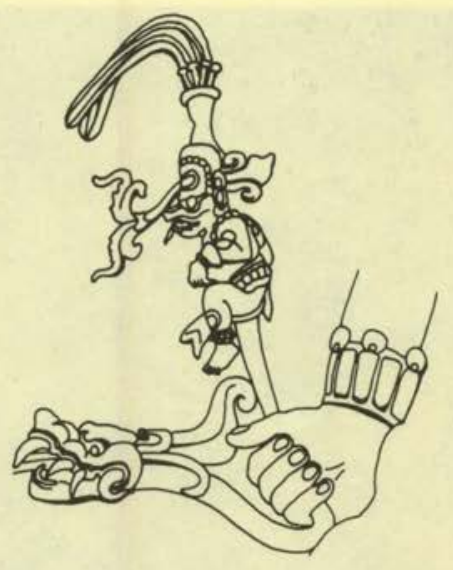

Figura 16. Cetro maniquí del altar D de Quiriguá

Como el nombre del dios K, Bolon Dz'acab, significa "Nueve Generaciones", parece aludir al linaje ilustre del gobernante que lo porta. Y además, el nombre del cetro es Canhel, ${ }^{15}$ el mismo del dragón en su aspecto creador, que aparece en la cosmogonía de los Libros de Chilam Balam, lo que confirma la identificación de las dos deidades.

Por otra parte, el dios del cetro maniquí, por la peculiaridad de su pierna, parece corresponder a Huracán, "Rayo de una Pierna", dios celeste quiché, que es la manifestación en lluvia de Gucumatz, o sea, un aspecto del dragón, y al que se llama también Corazón del Cielo, que significa "centro o eje, esencia del cielo"; por eso, aparece como el rector de las otras deidades del consejo divino quiché. ${ }^{16}$

Además, el dios $\mathrm{K}$ se representa en los cuchillos para el autosacrificio, aludiendo a la sangre que el hombre ofrece a los dioses. Y el dragón simboliza la sangre porque ésta fue considerada como la residencia del espíritu, de la energía que produce la vida y que los dioses dieron a los hombres al crearlos, por lo que éstos deben devolverla a los dioses para mantener su existencia.

Asimismo, el cetro maniquí simbolizó los ritos onanistas de estos gobernantes-chamanes, de ofrenda de semen a las deidades, ${ }^{17}$ por lo

${ }^{15}$ Véase De la Garza, Aves sagradas...

${ }^{16}$ Dice el Popol Vuh: “... estaban en el agua rodeados de claridad. Estaban ocultos bajo plumas verdes y azules, por eso se les llama Gucumatz... Entonces dispusieron la creación y crecimiento de los árboles y los bejucos y el nacimiento de la vida y la creación del hombre. Se dispuso así en las tinieblas y en la noche por el Corazón del Cielo, que se llama Huracán" (en De la Garza, Literatura maya, p. 13).

${ }^{17}$ Véase Coggins. "The Manikin Scepter..." 
que el dios $\mathrm{K}$ parece simbolizar la presencia del gran dios supremo dragón entre los hombres; la fertilidad sagrada en el mundo humano. Por eso es símbolo de sacralización de los gobernantes.

Y como presencia del poder sagrado de la fertilidad en el mundo humano, el dios $\mathrm{K}$ se asocia naturalmente con el maíz, la planta humana por excelencia, materia y sustento del hombre. Bolon Dz'acab, denominado por algunos G-2, es la deidad del Templo de la Cruz Foliada de Palenque, en cuya lápida se representa el nacimiento del maíz, al completarse su ciclo vital. Lo vemos ahí, naciendo de un caracol, al lado de la planta sagrada (figura 17).

La concordancia simbólica de todas estas figuras sagradas nos confirma que se trata efectivamente de un solo gran principio divino: la deidad suprema de la fertilidad, la energía vital del cosmos, manifestándose en múltiples formas.

Otro dios que parece ser un aspecto más del dragón es el Sol, que fue denominado en Yucatán Kinich Ahau, "Señor Ojo Solar" e Itzamná Kinich Ahau, "Señor Ojo Solar del Dragón", y que en sus representaciones plásticas lleva rasgos de serpiente en el rostro, o un pájaro serpiente en el tocado (figura 18).

Además, muchas veces porta otros atributos de Itzamná, como el símbolo triádico sobre su cabeza, por ejemplo, o bien su glifo está bajo el símbolo triádico en la cabeza del dragón, como señalamos arriba. $\mathrm{Y}$ otras veces aparece en forma de un hombre-águila (otra de sus epifanías animales), surgiendo de las fauces del dragón celeste (figura 19).

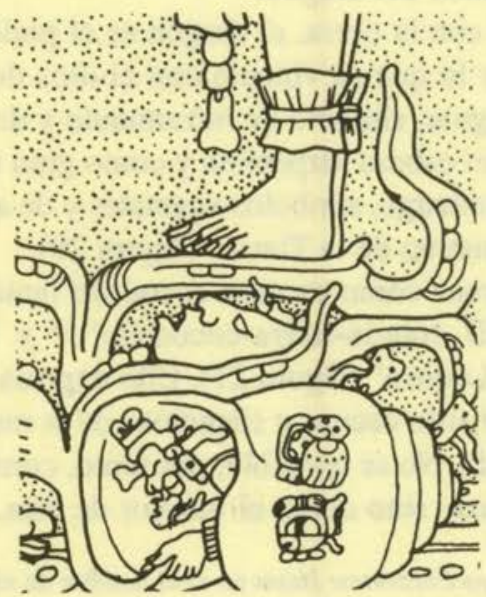

Figura 17. Detalle del tablero del Templo de la Cruz Foliada de Palenque 


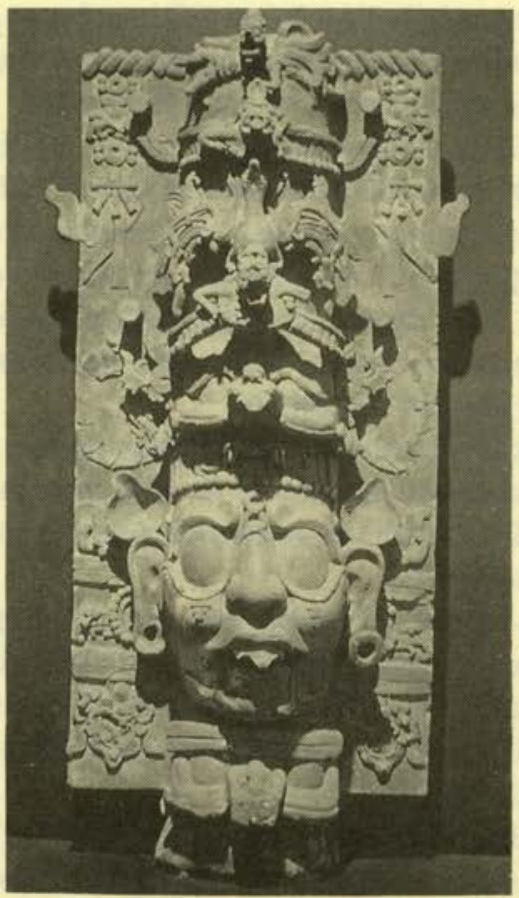

Figura 18. Portaincensario de Palenque

Así, la energía fertilizante del Sol parece haber sido vista como un aspecto de la sacralidad del dragón.

En su relación con la tierra, el dragón es el poder generador oculto en su interior, por lo que se vincula con el dios de la muerte que ahí reside, y con el jaguar, símbolo de inframundo y de cielo nocturno. Se representa como un cabeza serpentina y como gran mascarón descarnado que lleva, sin embargo, símbolos vegetales y de agua, al que algunos han llamado "Monstruo de la Tierra" (figura 20).

Y también aparece como un gran cocodrilo fantástico, ya que es Itzam Cab Ain, "El dragón-tierra-cocodrilo", ${ }^{18}$ y Chac Mumul Ain, "Gran Cocodrilo Lodoso" (figura 21). Ello expresa que el inframundo maya no es sólo el sitio oscuro y silencioso de la muerte, sino la caverna origen de la vida. No se concibió, por tanto, como un nivel cósmico separado de la tierra, sino como el interior de ésta, su gran útero, que

${ }^{18}$ Diccionario Maya Cordemex: Itsam no es el nombre de ningún lagarto, sino el de la deidad. Consideran, como nosotros, que es el mismo Itzamná, en su aspecto de dios terrestre (p. 272). 


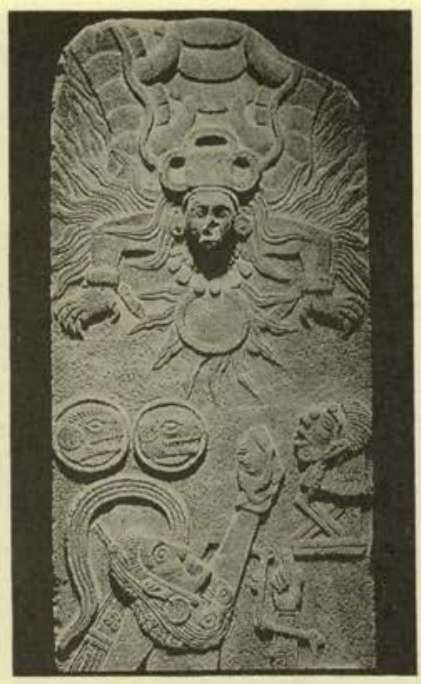

Figura 19. Estela 3 de Bilbao
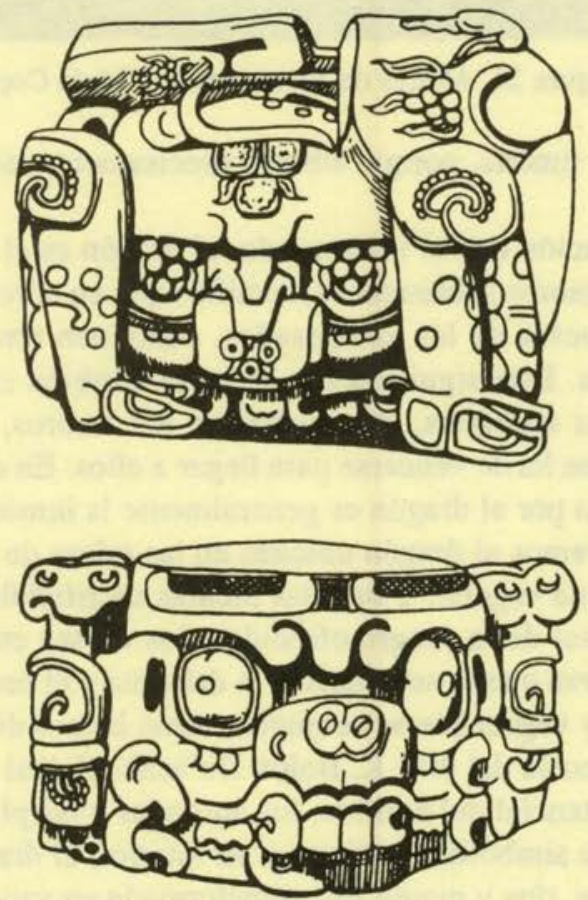

Figura 20. Estela 25 de Izapa 


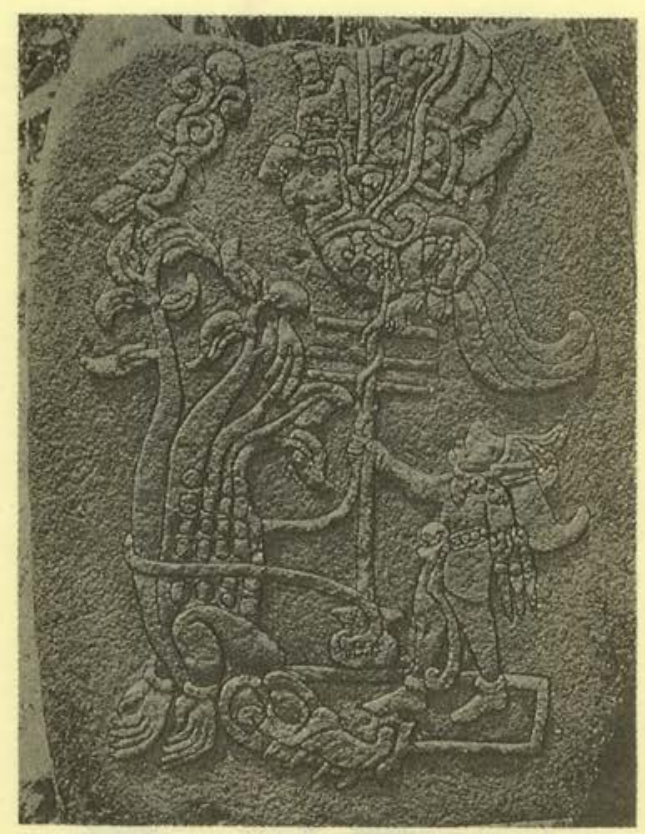

Figura 21. Altares de las estelas D y M de Copán

conjuga vida y muerte, porque alberga precisamente las semillas de la vida.

Por esta relación con el inframundo, el dragón es el guardián y poseedor de los tesoros subterráneos, semillas que en el reino de la muerte, entre los huesos de los antepasados, contienen renovadas posibilidades de vida. Esta significación se halla también en los dragones orientales y los europeos, que custodian los tesoros, constituyendo el adversario que ha de vencerse para llegar a ellos. En esos pueblos, el tesoro guardado por el dragón es generalmente la inmortalidad.

Y también vemos al dragón ubicado en las raíces de los árboles, infundiendo la vida vegetal. Y bajo las piedras sacrificiales, simbolizando la fuerza vital de la sangre ofrecida a los dioses en autosacrificio (figura 22), fuerza que es semejante a la del agua y el semen, por lo que sangre, semen y vegetación se conjugan, como hemos dicho, en la figura antropozoomorfa del dios K, Bolon Dz'acab, el cual expresa, así, el vínculo consustancial del hombre, los animales y las plantas.

Y además de simbolizar la tierra y su interior, el dragón representa el agua de lagos, ríos y mares, que transformada en vapor sube al cielo para concentrarse en nubes, y desde ahí desciende convertida en lluvia. 


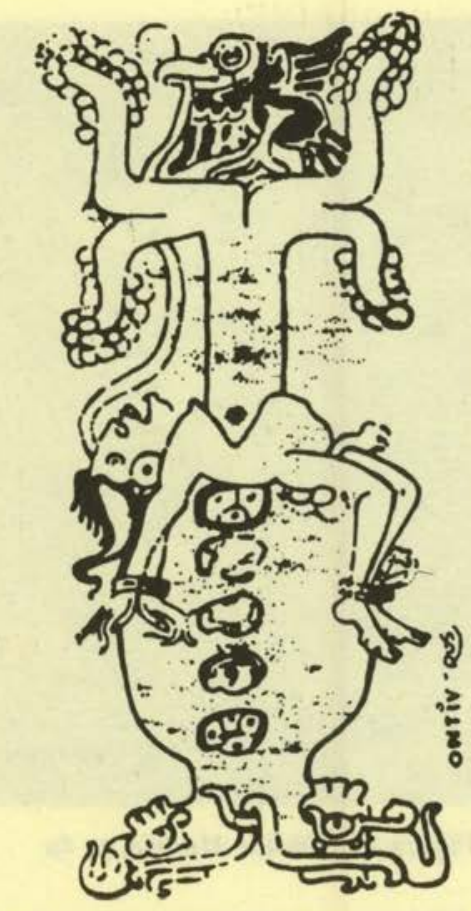

Figura 22. Códice de Dresde, p. 3a

El agua que circula entre el cielo y la tierra se simboliza como otra deidad antropomorfa derivada del dragón, el dios B, llamado Chaac y Ángel, el cual se dibuja en los códices con rasgos serpentinos en el rostro, generalmente de color azul y portando en la mano un hacha, una antorcha o una serpiente, que representan el rayo (figura 23). Esta deidad aparece a veces surgiendo de las fauces del dragón terrestre convertido en recipiente acuático, y también cayendo desde las fauces del dragón celeste, lo que simboliza su movimiento cíclico que fertiliza al mundo.

Chaac puede ser considerado como la manifestación en lluvia del dragón celeste, y se relaciona con el aspecto creador del dragón, Canhel-Huracán, en tanto que éste es símbolo del agua primordial con la cual los dioses formaron el mundo en el principio de los tiempos.

$\mathrm{Y}$ finalmente, como potencia celeste, creadora, ordenadora, el dragón es naturalmente el símbolo del gobernante, como lo es del emperador en China y en otros pueblos. ${ }^{19}$ Por estar asociado al rayo y a la fer-

${ }^{19}$ Por ejemplo, entre los celtas. 


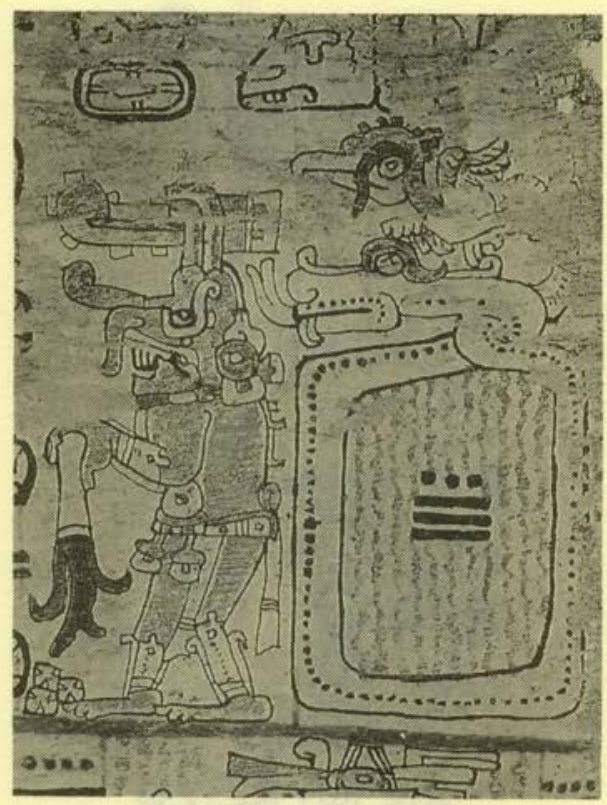

Figura 23. Códice Madrid, p. 4a

tilidad, simboliza las funciones reales y los ritmos de la vida que garantizan el orden y la prosperidad. El gobernante, representado en múltiples estelas del área central maya, lo porta sobre su pecho, en su forma de serpiente bicéfala; lo lleva en la mano como cetro maniquí, y forma parte de su tocado y otros atavíos, como cinturones, ajorcas e incluso, sandalias. El dragón simboliza, de este modo, la omnipotencia del gobernante, el que además se representa con rasgos de dragón en el rostro, para mostrar su asimilación a la deidad suprema (figura 24).

$\mathrm{Y}$ esta asimilación al poder sagrado de la fertilidad, o sacralización del mandatario, se daba a través de una iniciación, que también se muestra en las imágenes plásticas. En varias obras vemos al gobernante saliendo de las fauces del dragón, que a veces es bicéfalo, lo cual coincide con ritos de iniciación que se practicaron entre los mayas y que han pervivido hasta hoy, que consisten en que el iniciando es tragado por una gran serpiente que surge de un hormiguero, y luego es vomitado o excretado poseyendo ya las cualidades sobrenaturales de un chamán. ${ }^{20}$ Generalmente aparece a un lado una mujer que sostiene la vasija con los instrumentos para el autosacrificio, que era una de las

${ }^{20}$ Véase De la Garza, El universo sagrado..., cap. rx. 


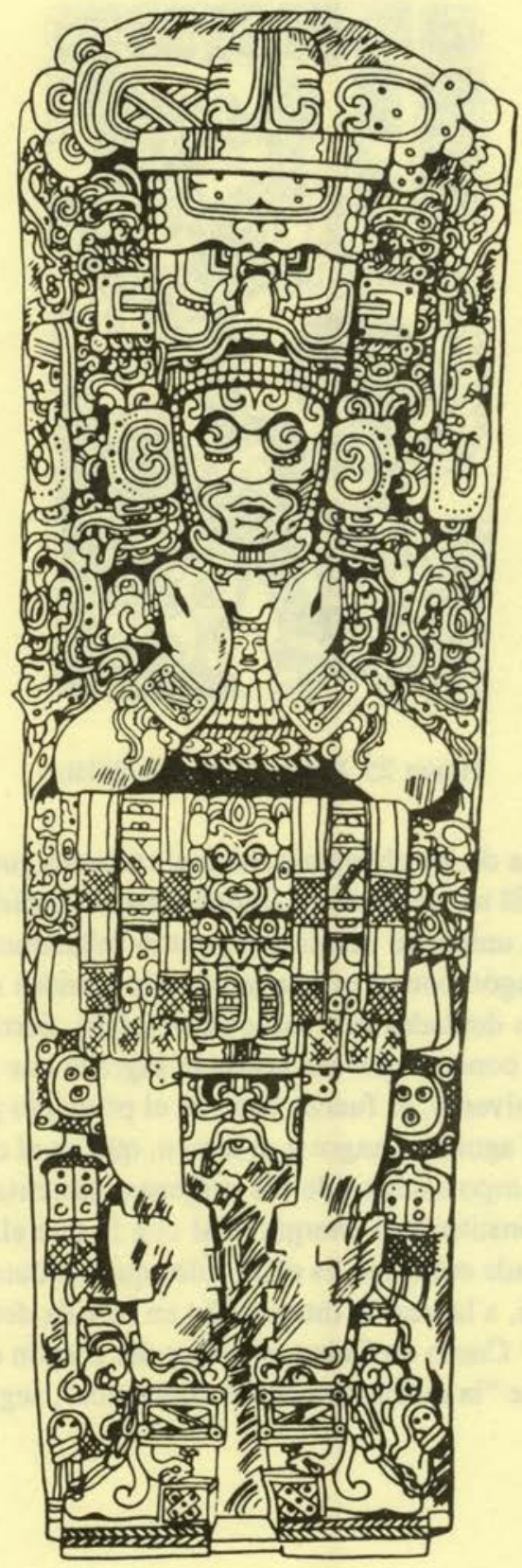

Figura 24. Estela I de Copán 


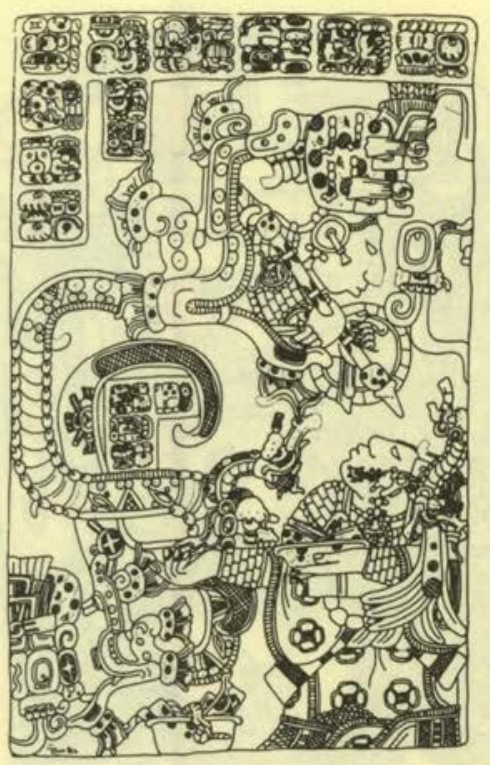

Figura 25. Dintel 25 de Yaxchilán

prácticas ascéticas de los chamanes, lo cual refuerza nuestra interpretación (figura 25). El ser vehículo de transfiguración espiritual es también una significación universal del dragón, como señalamos antes.

El lazo del dragón con el origen y los tres grandes niveles del cosmos, así como las deidades derivadas de él (cielo, tierra, Sol, sangre y lluvia), nos dan a conocer que esa potencia sagrada que impregna todos los estratos del universo, es fuerza vital, es el principio generador, ligado por ello con el agua, la sangre y el semen, que en el comienzo de los tiempos, en el tiempo estático de los orígenes, sustentaba a los dioses creadores; que constituyó la energía vital con la que ellos formaron el mundo, y que, desde entonces, es el impulso que produce continuamente la vida. Pero es, a la vez, la integración en la vida del silencioso reino de la muerte. ${ }^{21}$ Como en China, el poder del dragón entre los mayas es nada menos que "la resolución de los contrarios", según dijo Chuang Tse. 
Obras citadas

BarRera VÁsquez, Alfredo, et al.

1980 Diccionario maya Cordemex, Ediciones Cordemex, Mérida, Yucatán.

Chevalier, Jean, y Alain Gheerbrant

1991 Diccionario de los símbolos, Herder, Barcelona.

Coggins, Clemency

1988 "The Manikin Scepter: Emblem of Lineage", Estudios de Cultura Maya, pp. 123-157, unAM, Centro de Estudios Mayas, México.

De la Garza, Mercedes

1984 El universo sagrado de la serpiente entre los mayas, UNAM, Centro de Estudios Mayas, México.

1980 Literatura maya, Biblioteca Ayacucho 57, Edit. Galaxis, Barcelona.

1995 Aves sagradas de los mayas, unAM, Facultad de Filosofía y Letras / Centro de Estudios Mayas, México.

Graham, Ian, et al.

1977 Corpus of Maya Hieroglyphic Inscriptions, Peabody Museum of Archeology and Ethnology, Harvard University, Cambridge.

Hellmuth, Nicholas M.

1987 Monster und Menschen in der Maya-Kunst, Eine Ikonographie der alter Religionen Mexikos und Guatemalas, Akademische Druck und Verlagsanstalt, Graz.

LizanA, fray Bernardo de

1893 Historia de Yucatán. Devocionario de Nuestra Señora de Izamal y Conquista espiritual, Imprenta del Museo Nacional, México.

Maudslay, A. P.

1889- Biologia Centrali-Americana, 2 vols., Londres.

1902

Mode, Heinz

1980 Animales fabulosos y demonios, Fondo de Cultura Económica, México.

New Larousse Encyclopedia of Mythology

1981 Hamlyn, Londres.

Popol Vuh

1980 trad. Adrián Recinos, en De la Garza, Literatura maya. 
RoBicseK, Francis

1972 Copan, Home of the Mayan Gods, The Museum of the American Indian, Heye Fundation, Nueva York.

SCHELE, Linda

1978 "Genealogical Documentation on the Tri-figure Panels at Palenque", Tercera Mesa Redonda de Palenque, vol. IV, Herald Printers, Monterey, California.

Schellhas, Paul

1904 Representation of Deities of the Maya Manuscripts, Papers of the Peabody Museum of American Archaeology and Ethnology, Harvard University.

SosA, John

1984 "Astronomía sin telescopios. Conceptos mayas del orden astronómico", Estudios de Cultura Maya, vol. XV, Centro de Estudios Mayas, unam, México.

SPINDEN, Hebert Joseph

1957 Maya Art and Civilization, The Falcon's Wing Press, Indian Hills, Colorado.

ThOMPSON, J. Eric

1962 A Catalog of Maya Hieroglyphs, University of Oklahoma Press, Norman.

1975 Historia y religión de los mayas, Siglo XXI Editores, México.

WisDom, Charles

1961 Los chortís de Guatemala, Seminario de Integración Social Guatemalteca, Guatemala. 